IZA DP No. 6687

Bureaucratic Delay, Local-Level Monitoring, and Delivery of Small Infrastructure Projects: Evidence from a Field Experiment in Bolivia

Monica Yanez-Pagans

Carlos Gustavo Machicado

June 2012 


\title{
Bureaucratic Delay, Local-Level Monitoring, and Delivery of Small Infrastructure Projects: Evidence from a Field Experiment in Bolivia
}

\author{
Monica Yanez-Pagans \\ The World Bank \\ and IZA \\ Carlos Gustavo Machicado \\ Institute for Advanced Development Studies
}

Discussion Paper No. 6687

June 2012

IZA

P.O. Box 7240

53072 Bonn

Germany

Phone: +49-228-3894-0

Fax: +49-228-3894-180

E-mail: iza@iza.org

\begin{abstract}
Any opinions expressed here are those of the author(s) and not those of IZA. Research published in this series may include views on policy, but the institute itself takes no institutional policy positions.

The Institute for the Study of Labor (IZA) in Bonn is a local and virtual international research center and a place of communication between science, politics and business. IZA is an independent nonprofit organization supported by Deutsche Post Foundation. The center is associated with the University of Bonn and offers a stimulating research environment through its international network, workshops and conferences, data service, project support, research visits and doctoral program. IZA engages in (i) original and internationally competitive research in all fields of labor economics, (ii) development of policy concepts, and (iii) dissemination of research results and concepts to the interested public.
\end{abstract}

IZA Discussion Papers often represent preliminary work and are circulated to encourage discussion. Citation of such a paper should account for its provisional character. A revised version may be available directly from the author. 


\section{ABSTRACT}

\section{Bureaucratic Delay, Local-Level Monitoring, and Delivery of Small Infrastructure Projects: Evidence from a Field Experiment in Bolivia*}

This paper examines bureaucratic delay within the allocation of small infrastructure projects by sub-municipal governments in Bolivia, and it presents a randomized field experiment designed to improve public service delivery by promoting voice, transparency, and accountability among grassroots organizations. The experiment consists of randomly providing sub-municipal governments with a mailing tracking system, which provides public officials and grassroots organizations real- time information about the processing of small infrastructure projects requests by sub-municipal governments. The objective of this intervention is twofold. First, is to facilitate the involvement of grassroots organizations in the process of reviewing, tracking, and monitoring small infrastructure project allocations. Second, is to explicitly alter the probability of detecting inefficient administrative practices within district councils and, therefore, to implicitly increase the expected cost of engaging in such practices among public officials. The findings of this paper suggest that monitoring tools that promote access to information by citizens might play a critical role in improving public service delivery outcomes. Yet, in settings where mechanisms of local accountability are subject to be captured by local elites or are weak, monitoring tools might have limited capacity to improve outcomes. In such settings, major transparency related reforms might be needed to improve public service delivery outcomes.

JEL Classification: D73, C93, H76

Keywords: Bolivia, transparency, accountability, local-level monitoring, bureaucratic delay

Corresponding author:

Monica Yanez-Pagans

World Bank

1818 H Street, NW

Washington, DC 20433

USA

E-mail: myanezpagans@worldbank.org

\footnotetext{
* We are very grateful to Jaime Duran, Richard Duran, Mario Duran, Fanny Nina, Waldo Mendoza, Willmar Pimentel, and Andrea Alvarez for their invaluable help coordinating fieldwork and implementing the project. For their very helpful comments and suggestions, we thank Mary ArendsKuenning, Kathy Baylis, Alberto Chong, Jeffrey Douglas, Craig Gundersen, Ron Laschever, Nolan Miller, and Emmanuel Skoufias. This project was funded and undertaken as part of the Latin American and Caribbean Research Network of the Inter-American Development Bank. This paper has been screened to ensure that no confidential information is revealed.
} 


\section{Introduction}

Decentralization of public services to local governments and community participation in the monitoring of the delivery is now regarded as the key to improved social service provision in developing countries. ${ }^{1}$ The idea behind community participation in the monitoring of public service delivery is that community members are the people who ultimately benefit from a successful program and, therefore, they are the ones with better incentives to monitor, and should be given this responsibility (Stiglitz, 2002). The vision of community participation in the monitoring of public services is now indeed one of the cornerstones of the World Bank's Comprehensive Development Framework (Philip et al. 2001). ${ }^{2}$ Despite the enthusiasm for community-level monitoring, however, there are many skeptics of the potential of these type of schemes to improve public service delivery. Bardhan (2002), Gong (2002), and others, for instance, suggest that the use of grassroots participation in monitoring might promote locally based corruption and even facilitate organized crime. Banerjee et al. (2004) and Banerjee et al. (2010) show that overcoming the collective action problem inherent to any type of community level monitoring scheme might be very challenging in practice. ${ }^{3}$

During the last couple of years, a small but growing experimental literature looking at how to address the collective action problem inherent to community monitoring schemes has begun to appear. The results, however, are not encouraging. ${ }^{4}$ One of the experiments, for instance, focuses on addressing high absence rates among nurses assigned to community health centers in India (Banerjee et al., 2004). The experiment consisted in paying a member of the community to randomly check (on a weekly basis) whether the nurse assigned to the health center was present or not and, if not, to find out if she could be found somewhere around in the village. The idea behind this experiment was to let villagers choose how to use the monitoring information the experiment was generating. No attempt was made to impose an external reward system for the nurses based on the monitoring information. At the end of the experiment, average absence rates in both treatment and control health centers turned out to be almost identical. Community monitoring by itself was clearly not enough in this setting to reduce absenteeism among health workers.

A second related study looks at the collective action problem within the context of the current flagship program of universal primary education in India (Banerjee et al., 2010). This flagship program organizes locally elected leaders and parents of children enrolled in public schools into committees, and gives them power over resource allocation and management of school performance. The experiment looks at alternative interventions aimed at encouraging participation of parents and local leaders on these committees, including provision of information, training of community members, and training and organization of volunteers to hold remedial reading camps for illiterate children. The results

\footnotetext{
${ }^{1}$ See, for instance, Foster and Rosenzweig (2001), Galasso and Ravallion (2005), and Bardhan and Mookherjee (2006).

${ }^{2}$ The entire World Bank's World Development Report, in 2004, also advocated for putting users of public services at the center of the provision as the keystones for improved public service delivery (World Bank, 2004).

${ }^{3}$ The collective action problem in this setting refers to the fact that monitoring is a public good and, therefore, is prone to free-rider problems.

${ }^{4} \mathrm{~A}$ large number of studies present randomized experiments designed to address the problem of absence of teachers and health providers in developing countries. Most of these studies are summarized in Banerjee and Duflo (2006).
} 
of the experiment were overall not encouraging. None of the interventions resulted in a significant impact on community involvement, neither on teacher effort or learning outcomes. The authors suggest, therefore, that although communities care about education and are willing to do something to improve school quality, they face important constraints to participate in the monitoring.

There is also a small experimental literature looking at the effects of increased public access to information as a tool to improved public service delivery. This literature mainly has focused on assessing the extent to which facilitating access to information by users might help reduce capture and misuse of public funds. This literature is more encouraging and provides convincing evidence that higher levels of information and accountability might be able to improve public service delivery by limiting opportunities for corruption at the local level. ${ }^{5}$ Using a unique World Bank public expenditure tracking survey, Reinikka and Svensson (2004a) document that for every dollar spent by the central government in schools, schools in Uganda receive indeed only 20 cents on average. To explore ways in which to deal with this missing funds problem, the authors take advantage of an unusual policy experiment to assess the effect of improved access to information on reducing diversion of public funds (Reinikka and Svensson, 2004b). The policy experiment consists of a newspaper campaign designed to boost the ability of schools and parents to monitor the handling of school funds from the central to the local level. By using proximity to a newspaper outlet as an instrument for exposure to the information campaign, they find that public access to information is a powerful deterrent of corrupt behavior. The diversion of public funds from schools is reduced from 80 to 20 percent throughout the six years of their study.

A related study presents a randomized experiment looking at the effectiveness of a bottom-up monitoring scheme in reducing missing funds within the provision of village road projects in Indonesia (Olken, 2007). The experiment consisted of encouraging village members (through letters of invitation) to participate in accountability meetings organized regularly by local leaders. This intervention is then contrasted with a top-down monitoring scheme consisting of informing villages ex-ante that they will be subject to an audit visit upon completion of the projects. Although the letters of invitation intervention proved successful at raising community participation in the monitoring of village infrastructure projects, it did not result in a significant reduction in overall missing expenditures. Instead, the top-down monitoring scheme proved quite successful in these setting at curbing local corruption. The author suggests, therefore, that when incentives to monitor are weak such as in the case of infrastructure projects provision, top-down approaches to monitoring may be much more effective.

The previous literature identifies at least three necessary conditions for access to information to translate into improved public service delivery. First, beneficiaries must greatly value the public service in question. It has been suggested, for instance, that community participation might have not worked well to improve education outcomes because its benefits are not tangible for the community. Second, local leaders must have strong incentives to engage in monitoring activities to overcome the collective action problem. de Janvry, Finan, and Sadoulet (2010), for instance, present evidence

\footnotetext{
${ }^{5}$ Rose-Ackerman (2005) provides a summary of much of the non-causal work on voice, transparency, and public service delivery to date.
} 
that local leaders' political incentives significantly affect the educational outcomes of a decentralized conditional cash transfer program in Brazil. Third, formal mechanisms of voicing complaints and punishing providers must be in place. If information and accountability mechanisms are weak, as is common in many developing countries, beneficiaries will not have incentives to engage in monitoring activities.

This paper examines bureaucratic delay within the allocation of small infrastructure projects by sub-municipal governments in Bolivia, and it presents a randomized field experiment designed to reduce bureaucratic delay by promoting transparency and accountability among grassroots organizations. Our experiment consists of randomly providing district councils (or sub-municipal governments) with a tracking system, which provides public officials and grassroots organizations real-time information on the processing of small infrastructure projects requests by district councils. The objective of this intervention is twofold. First, is to facilitate the involvement of grassroots organizations in the process of reviewing, tracking, and monitoring small infrastructure projects allocations. Second, is to explicitly alter the probability of detecting inefficient administrative practices by public officials within district councils and, therefore, to implicitly increase the expected cost of engaging in such practices among public officials.

Bolivia presents an ideal setting in which to study this because of the radical and well-defined decentralization reform process introduced in 1994. The Bolivian decentralization was linked to a farreaching law of popular participation, which dramatically empowered citizens by granting grassroots organizations the right to participate in the planning, budgeting, and monitoring of public services. Further, the law granted grassroots organizations the right to discipline sub-municipal providers by giving them veto power over sub-municipal budgets and budget reports to ensure both that funds were well spent and that local elites did not capture a disproportionate amount of resources. The Bolivian decentralization and the law of popular participation have been widely studied and are considered the landmark for the design of decentralization reforms in developing countries (Bardhan, 2002). In addition, Bolivia provides a unique opportunity in which to empirically assess the effect of improved information on public service delivery because all of the conditions previously discussed as necessary for effective local-level monitoring hold in this setting. First, there is a very large demand for small local infrastructure projects involving community participation, and their delivery is something community members greatly value. Moreover, its delivery is something very visible for the community as a whole and its benefits immediately observable for the users (street lighting for instance). Second, the delivery of small infrastructure projects is pervasively used by local leaders, in this setting, as a political investment to make it to the district council office. This creates huge personal incentives for local leaders to engage in monitoring activities for the provision of these goods on behalf of their communities. Third, the decentralization and law of popular participation introduced well established formal mechanisms to voice complaints and to discipline sub-municipal governments.

The remainder of this paper is organized as follows. Section 2 discusses the setting of the study. Section 3 describes the experimental design, sampling, and randomization design. Section 4 presents the estimation framework. Section 5 describes the data. Sections 6 presents the experimental results. 
Section 7 presents the interpretation of the results. Section 8 concludes.

\section{Setting of the study}

In 1994, as part of a global trend, the Bolivian government instituted an ambitious decentralization reform from the central to the sub-municipal level which, among several things, sought to improve government efficiency in the delivery of public services. The decentralization process transferred the provision of public services and infrastructure projects to the municipalities and was associated with massive shifts of public resources from the central to the sub-municipal governments. ${ }^{6}$ As part of the decentralization process, hundreds of new municipalities were created and innovative institutions of local governance developed. To ensure that the decentralization process did not translate into an entrenchment of elites, however, the law of popular participation mandated the creation of oversight committees (comités de vigilancia). Oversight committees are responsible for overseeing that at least 85 percent of the sub-municipal public spending is used towards infrastructure projects and social investments, and for re-balancing resources in favor of poorer districts. Oversight committees operate by consensus, and give any single member veto power over the approval of district development plans and budget reports. Depending on the size of the municipality, the oversight committees have between three to ten members who are democratically elected among local leaders.

The Bolivian decentralization and the law of popular participation have been widely studied and are considered the landmark for the design of decentralization reforms in developing countries (Bardhan, 2002). The distribution of political power resulting from this reform has been associated with large increases in the magnitude of public spending (Robinson (2008) and Faguet and Sanchez (2008)), the responsiveness of public investments to local needs (Faguet, 2004), and the allocation of social spending towards smaller and poorer municipalities (Faguet, 2006). Yet, the distribution of political power is also believed to have had important implications for the allocation of resources at the local level. In particular, with greater resources going to local governments, opportunities for local elites to use their influence to benefit from a disproportionate share of public spending multiplied. The legislation of this reform assumed that local participation in monitoring would act as a brake for misallocation of resources because local organizations could stand for the grassroots and represent their interests. However, in a qualitative study, Kohl (2003) suggests that the Bolivian decentralization and law of popular participation resulted in the entrenchment of local elites and the decentralization of corruption rather than on the promotion of local development.

The city of El Alto, the setting for this study, is the third largest city in Bolivia by population size and also one of the poorest in the country - 67 percent of its residents live below the poverty line. As of 2009, the city was home to close to 0.93 million people, most of whom were first to third generation migrants from the surrounding countryside and mining areas of the capital city of

\footnotetext{
${ }^{6}$ The legal framework of these reforms was established by the Ley de Participación Popular (Law of Popular Participation) and the Ley de Descentralización Administrativa (Law of Administrative Decentralization).
} 
La Paz. El Alto is the largest indigenous city in Latin America (82 percent of its residents are of indigenous descent) and it is well known for retaining a strong indigenous cultural identity based on a deep-rooted sense of community (Lazar, 2007). The city of El Alto is highly organized and, for the majority of their residents, their relationship with the sub-municipal government is shaped by their membership in the neighborhood associations (Lazar, 2006). Neighborhood associations are the main interface between the sub-municipal governments and the civil society in the urban areas, and are the formal institutions through which to channel demands for small infrastructure projects to the sub-municipal governments. ${ }^{7}$ Neighborhood associations in the city of El Alto are, by far, the strongest and most well organized in the country. They are also believed to be one of the most effective grassroots organizations in the world (Romer, 2008). El Alto comprises more than 630 neighborhood associations, each of which is headed by a local leader (presidente) who is democratically elected every two years among citizens residing in the neighborhood. The position of neighborhood president is voluntary, unpaid, and normally carries high social recognition (Lazar, 2004). Neighborhood presidents meet regularly with each other and their constituents, and their one major objective throughout the year is to obtain small infrastructure projects for their neighborhoods. The city of El Alto has several accountability mechanisms regarding local government performance for their residents. The main accountability mechanism for neighborhood association members are the neighborhood accountability meetings (Asambleas Vecinales), which are organized periodically by neighborhood presidents. Then there are also the district accountability meetings (Asambleas distritales), which are jointly organized by neighborhood presidents belonging to a district. Accountability meetings are opened to all citizens. Many different topics are openly discussed in these meetings, including the delivery of small infrastructure projects for the neighborhoods and corruption problems.

The city of El Alto is divided into 13 administrative districts or district councils (Subalcaldías), each of whom is in charge of the provision of small infrastructure projects to the neighborhoods. District councils are the lowest administrative level below the sub-municipal government and function under the direction of a district major or head of district council (Subalcalde), who is democratically elected every two years among neighborhood presidents from the district. This creates huge political incentives for neighborhood presidents to get actively engaged in local-level decision making concerning their neighborhoods of residence. Traditionally, the capacity to obtain infrastructure projects for a neighborhood is associated with the ability to perform well as head of the district council. District councils in the city of El Alto are classified as either urban (8 out of the 13), peri-urban (3 out of the 13), or rural (2 out of the 13) based on their proximity to the capital and adjacent city of La Paz. Each district council works with an annual budget assigned by the Municipal Government of El Alto, based on population size. The use of this budget within each district council is governed by the annual District Development Plan (Plan Operativo Anual), whose planning and budgeting are jointly elaborated by the head of the district council, the neighborhood presidents, and the members of the

\footnotetext{
${ }^{7}$ Neighborhood associations were not conceived as a result of the law of popular participation but rather have a long history of union power and organization in the city of El Alto. Further, they have dominated the community life of this city for decades (Blanes, 1998).
} 
oversight committees. ${ }^{8}$ The district development plans set clear and specific goals for district councils related to the provision of large infrastructure projects for the district and set aside a fraction of the budget for small infrastructure projects (approximately 20 percent).

Small infrastructure projects are basic infrastructure projects whose total cost does not exceed BS 200,000 (USD 28,500). Table 1 presents a summary of the composition of small infrastructure projects we look at in this paper. These include street-lighting, sewage treatment, culverts, trench digging, tree planting and landscaping, construction of retention walls, groundwork, shallow excavations, etc. In contrast to large infrastructure projects, the allocation of small infrastructure projects is not included in the district development plans but rather determined at general assemblies (Asambleas Generales) throughout the year. The main pre-requisite for a small infrastructure project to be submitted to the general assembly for consideration is to successfully complete a pre-certification process at the district council. The pre-certification process endorses a project for review at general assemblies and consists of a series of administrative steps involving several revisions and inspections by public officials to the field. The different steps aimed by pre-certifying projects is to make sure that the project is eligible (i.e. its total budget is less than BS 200,000), feasible (i.e. the district council has the operating capacity to deliver such project in the proposed timeline), and that it will benefit to a relatively large number of people in the district (though it is not exactly clear what "large" means in this context in practice, this usually is a discretionary decision made by of the head of the district council).

The pre-certification process is officially initiated with the submission of a request letter to the head of the district council by the president representing the citizens residing in the neighborhood. The letter is manually registered in one of the many different incoming mailing notebooks that public officials working within the district councils keep at one moment in time (libros de correspondencia). After the registration of the letter, this is sent to one of the many different Units within the district councils working in the pre-certification of small infrastructure projects requests. The steps for precertification are specific to each type of request and, as the pre-certification process moves forward, the tracking is recorded manually in different incoming and outgoing mailing notebooks across the different Units. In general, mailing notebooks are neither harmonized nor synchronized, which makes tracking very time consuming and complicated for the neighborhood president. More often than not, these mailing notebooks have inaccurate, out of date, and discrepant information across Units (Figure 1 show samples of these manual mailing notebooks). Consequently, although neighborhood presidents have strong incentives to track their pre-certification project requests, they face substantial constraints when participating in the monitoring. Not surprisingly, therefore, neighborhood presidents have traditionally complained about the lack of reliable and transparent information to track their requests within district councils.

This manual mailing system, and more generally the lack of formal mechanisms to enhance transparency and local accountability, creates great scope for inefficiency, exercise of discretion, and bureaucratic delay within the district councils. In particular, as monitoring for the neighborhood president is

\footnotetext{
${ }^{8}$ The elaboration of district development plans usually start in September of each year, and are endorsed and approved by the sub-municipal government by mid-to-end November.
} 
so costly, public officials have incentives to and usually do avoid taking care of their responsibilities by sending the letters back and forth between Units (this is known as the ping-pong practice among public officials). Bloated bureaucratic structures and inadequate human resource capacity at district councils are also common, which significantly hamper efficiency within the delivery of public services. Further, political connections are considered valuable assets to facilitate the provision of small infrastructure projects. Some neighborhood associations are believed to have become increasingly politicized and respond more to self-interest of local leaders rather than to the interests of the collectivity (Lazar, 2005). At least, this is what many believe, and neighborhood associations are increasingly coming to the heart of this debate.

\section{Design of the experiment}

The experiment consisted of randomly providing district councils with a mailing tracking system (Chaskinet), which promotes transparency and accountability by providing neighborhood associations and public officials real-time information on the status of their small infrastructure projects pre-certification requests. ${ }^{9}$ The Chaskinet also allows users to access user-friendly summary statistics on pre-certification requests and outcomes of the process by type of project. The idea of this experiment was to let neighborhood associations choose how to use the information the Chaskinet was generating - no attempt was made to impose an external reward/punishment system based on the information generated by the Chaskinet. The use of the Chaskinet does not directly enable neighborhood associations to recognize inefficiencies and favoritisms, but rather affects social control indirectly through three channels. First, the Chaskinet reduces the opportunity cost of neighborhood presidents to finding out about the status of a pre-certification requests and, therefore, it implicitly facilitates their involvement in the process of reviewing, tracking, and monitoring small infrastructure projects allocations. Second, the Chaskinet eliminates the possibility that public officials lie about the location and status of a request and, therefore, it implicitly reduces the probability of them engaging in ping-pong practices. ${ }^{10}$ Third, by explicitly altering the probability of detecting endogenous bureaucratic delay, the Chaskinet increases the expected cost of engaging in inefficient and ping-pong practices among public officials.

The Chaskinet is a simple and easy-to-use tracking software system. The system involves usernames and passwords assigned to each public official working at the district council and, therefore, it can easily provide real-time information on small infrastructure project allocations. Every time the district council received a pre-certification request, it was introduced into the system, which assigned a sequential unique tracking number to each of the requests. This tracking number was given to the neighborhood president submitting the request and could be used to track the request throughout

\footnotetext{
${ }^{9}$ The chaskis were agile and highly-trained runners that were dispatched along thousands of miles to deliver messages throughout the Inca Empire, which extended throughout most of the present-day Bolivia.

${ }^{10}$ The reason why the Chaskinet eliminates the possibility that public officials lie about the location and status of a request is because the system generates real-time information about the location and status of a request.
} 
all of the pre-certification process (i.e. analogous to any standard mailing tracking system in the United States). Neighborhood presidents could access the Chaskinet by either using a computer terminal specifically located at each of the district councils to track the requests, or by approaching any public official at the district council to ask about the status of their requests (i.e. by doing exactly the same thing they were doing before the Chaskinet came into effect). To the extent that neighborhood presidents can access the Chaskinet using any of the above two procedures, there should be no correlation between the ability to operate a computer and the use of the Chaskinet. ${ }^{11}$

\subsection{Sampling and randomization design}

The sampling for the study consists of a matched-pair design, with randomization occurring at the level of district council. The primary sampling frame consisted of the list of the 11 urban and periurban district councils in the city of El Alto. In a first step, we constituted five pairs of district councils by matching district councils according to urban/peri-urban status and size as measured by the total budget for the 2009 district development plan. This led us to discard from the sampling frame the peri-urban district council, which looked most dissimilar in size to their counterparts. The reason why we chose a pair-matching sampling design over simple random sampling is mainly because we wanted to assure balance on the budget covariate as we believed inefficiencies might operate quite differently across distinct district council sizes. Randomization was clustered at the district council level to avoid both anticipation effects and to make implementation feasible. To this end, the main limitation of the study is the small power of the experiment arising from the small number of clusters in our data. ${ }^{12}$

In a second step of the randomization, we randomly selected one district council within each pair to receive an encouragement to participate in the experiment. The encouragement consisted of a visit to the district council to present detailed information on the Chaskinet and its capabilities to the head of the district council. At the end of the visit, the head of the district council was offered the opportunity to participate in the experiment. In exchange for participation, the district council was offered free wiring installation and network connection for all of the computers in the district council, and free training and support on the use of the system. Further, the head of the district council was told that this was a one-time offer, that the district was selected to participate by lottery, and that the Chaskinet was not going to be offered to him or any other district at any other point in time in the future. Out of the five districts encouraged to participate, only four accepted the offer. These four comprise all of the urban districts in El Alto except for the peri-urban pair, which was excluded from the experiment.

The final sample is composed of a total of four treated and four control district councils. Table

\footnotetext{
${ }^{11}$ The probability of public officials providing misleading information on the status of a request to neighborhood presidents is very unlikely given that sub-municipal government offices are very small in this context and neighborhood presidents in practice are able to directly monitor the provision of information by public officials.

${ }^{12}$ Section 4 discusses how we address the issue of low power in the estimation of the Chaskinet effects.
} 
2 displays a summary of the experimental design. For each of the four matched-pairs included in the study, each pair of rows shows the total number of neighborhood associations in the district and the total number of neighborhood associations actively engaged in the demand of pre-certification requests by Chaskinet status. The distribution of neighborhood associations reported in this table confirm that overall there is good balance in the number of neighborhood associations in each pair across Chaskinet status.

An important note to make here is that the introduction of the Chaskinet was announced to district councils and neighborhood associations after development plans were finalized for that fiscal year. To that end, the choice of what type of large infrastructure projects to fund during that fiscal year, as well as the planned budget for small infrastructure projects, should all be viewed as exogenous with respect to the experiment. Although treatment district councils were randomized according to the procedure described above, it is useful to examine whether the Chaskinet status is ex-post correlated with some key district council and neighborhood association characteristics. Table 3 explores this by reporting probit regression marginal effects for the probability of being randomized into treatment as a function of 11 neighborhood association and 5 district council characteristics of interest. ${ }^{13}$. As expected given the randomization, these marginal effects are small and not jointly significant predictors of the Chaskinet at standard levels (joint $p$-values 0.21, 0.17, and 0.10). However, the main experimental results remain largely unchanged when adding these covariates as control variables (access to electricity and population size).

\section{Estimation framework}

The causal impact of the Chaskinet is estimated via ordinary least squares using the following regression model for neighborhood association $n$, in district council $d$, submitting a pre-certification request for infrastructure project of type $t$ :

$$
y_{n d t}=\beta_{0}+\beta_{1} \text { Chaskinet }_{d}+\kappa_{t}+\xi_{n d t}
$$

where y is either: (i) indicator for whether the pre-certification process was successfully completed, (ii) number of days pre-certification requests take to get completed, or (iii) number of public officials involved in the pre-certification completion process (this allows us to assess the prevalence of ping-pong practices among public officials); Chaskinet is a treatment indicator at the district council level; $\kappa_{t}$ is a vector of 19 type of infrastructure project fixed effects; and $\xi_{n d t}$ is a normally distributed error term independently and identically distributed over $n, d$, and $t$, and clustered at the neighborhood association level. As all district councils had the same probability of receiving the Chaskinet independently of the pair they were in, the probability of receiving the Chaskinet is orthogonal to any

\footnotetext{
${ }^{13}$ These variables were the variables used at the baseline to design the sample, and were specified before the experimental data used here were collected.
} 
matched-pair level or district council level variable. To this end, controlling for strata is not necessary for the analysis to be consistent, but it may help to reduce standard errors. In the subsequent analysis, we present different specifications of the above regression model based on whether we respect the blocking structure of the sampling design or not.

As the number of clusters in our experiment is so small, an important issue in this setting is how to preserve power when estimating the cluster-robust variance matrix. Kernan et al. (1999) and Wooldridge (2003) emphasize that relying on asymptotics for hypothesis testing when the number of clusters is small can be very misleading as it tends to result in an over-rejection of the null hypothesis. The finite-sample properties of the standard cluster-robust variance estimators have been suggested to work reasonably well only when the number of clusters is larger than 50 (Bertrand, Duflo, and Mullainathan (2004) and Kezdi (2005)). To preserve power, we use exact permutation inference to estimate the $p$-values associated with the Chaskinet effects (e.g. Rosenbaum (2002), Kremer et al. (2006), and Donald and Lang (2007)). Permutation inference consists of estimating the $p$-values of the treatment effect by estimating a reference distribution of the treatment effect by randomly permuting treatment status across district councils without replacement under the assumption that the Chaskinet has no effect on the outcomes of interest. Yet, although permutation inference is particularly useful when the treatment effect is small, this technique has low power relative to parametric approaches when the true effect is large (as it does not put even a minimal structure on the error term).

The use of the Chaskinet affects bureaucratic delay by inducing a reduction in both ping-pong practices among public officials and the exercise of discretion by the head of the district council. The experimental design, however, does not directly enable us to separate these two effects. To gain some insights into the mechanisms underlying the experimental data, however, we conduct focus groups to collect data on political connections within districts. The idea of these data is to construct a measure of local elites at the neighborhood president level. Local elites are broadly defined as locally-based individuals with disproportionate access to social, political or economic power. These data on local elites are then used to test for whether the effects of the Chaskinet vary across the level of political connections of the neighborhood association. If bureaucratic delay and successful completion of a pre-certification request are merely explained by random inefficiencies within district councils such as incompetence or ping-pong practices, we might expect to observe that the Chaskinet has a similar effect across all neighborhood associations independently of their elite status. We formally test for the possibility that the Chaskinet effects might vary systematically based on the level of political connectedness by estimating the following equation via ordinary least squares:

$$
y_{n d t}=\beta_{0}+\beta_{1}\left(\text { Chaskinet }_{d} * \text { Elite }_{n d}\right)+\beta_{2} \text { Chaskinet }_{d}+\beta_{3} \text { Elite }_{n d}+\kappa_{t}+\xi_{n d t}
$$

where Elite is an elite indicator at the neighborhood president level. ${ }^{14}$ The parameter of interest

\footnotetext{
${ }^{14}$ Based on the qualitative data collected in the focus groups, neighborhood presidents were classified by the survey firm into an elite and a non-elite group based on their political connections. We use this classification throughout our data analysis.
} 
in this specification is $\beta_{1}$, which provides an estimate of the average difference in the outcome variable in the Chaskinet group from elite to non-elite groups relative to changes in the outcome variable in the control group over the same groups. If the Chaskinet is having a favorable effect by preventing the exercise of discretion within the allocation of small infrastructure projects as measured by the endorsement of pre-certification requests, then we would expect to observe that the interaction effect between the Chaskinet and the elite indicator is negative (i.e. $\beta_{1}<0$ ). In contrast, if the Chaskinet is not preventing the exercise of discretion, then we would expect to observe that the interaction effect between the Chaskinet and the elite indicator is zero or positive (i.e. $\beta_{1} \geq 0$ ). Moreover, if the Chaskinet is having a favorable effect by reducing bureaucratic delay gaps between elites and non-elites as measured by number of days and number of public officials involved in the processing of requests, then we would expect to observe that the interaction effect between the Chaskinet and the elite indicator is positive (i.e. $\beta_{1}>0$ ). Conversely, if the Chaskinet is increasing bureaucratic delay gaps between elites and nonelites, then we would expect to observe that the interaction effect between the Chaskinet and the elite indicator is zero or negative (i.e. $\beta_{1} \leq 0$ ).

\section{Data}

The data for this study come from multiple sources and combines different methods of inquiry. The primary data include the following: (i) pre-certification for small infrastructure projects data; and (ii) political connections data. The secondary data include the following: (i) administrative data on public officials, neighborhood presidents, and district development plans; and (ii) Census data on living standards at the neighborhood association level. All data were collected between October 2009 and July 2010. The data for the first month (October 2009) correspond to the baseline data and the data for the remaining months (December 2010 to July 2010) correspond to the experimental data. The collection of the baseline data started just after the completion of district development plans for the fiscal year of our analysis.

\subsection{Pre-certification data for small infrastructure projects}

The pre-certification requests data for the treatment districts were straightforward to compile and was directly collected from the Chaskinet. These data were collected by the field team on a weekly basis throughout the implementation of the project. These data include the following: (i) district council number; (ii) unique tracking number; (iii) name of the neighborhood association submitting the request; (iv) name of the neighborhood president submitting the request; (v) type of infrastructure project; and (vi) tracking information including date of pre-certification request submitted, completion date, outcome of the pre-certification request, and number of public officials needed to complete the pre-certification process. The data for the control district councils and all of the baseline data were more challenging to compile, and it involved the manual gathering of administrative information from the district council mailing records to construct a dataset which closely overlapped that generated by 
the Chaskinet. The construction of this dataset involved mainly two activities: digitally photographing the entire district council mailing notebooks page by page (3,373 pictures), and transcribing all of the information into a digital format. The photographing of the mailing books involved devising a unique photography tracking number, which allowed keeping track of all of the pages to minimize errors during the transcription phase. To verify the quality of the data, external auditors performed several random checks. These random checks consisted of visits to the district councils to verify that the information in the dataset was consistent with what was observed in the mailing books. ${ }^{15}$

\subsection{Political connections data}

The data on political connections were gathered using focus groups conducted between May and June of 2010. Participants were randomly invited to participate and included neighborhood presidents, public officials, and members of the oversight committees. To ensure high attendance rates, the focus groups were organized in the late afternoon during weekdays, and at all times included at least 20 percent of the neighborhood presidents, public officials, and members of the oversight committees. The discussion in the focus groups was focused on collecting information about political support, political connections, and elite groups in the districts. The focus groups encouraged participants to openly discuss the dynamics of small infrastructure projects allocations, their perceptions about the pre-certification processes, and how political engagement might facilitate the successful completion of a pre-certification request. At the end of the meetings, all participants were invited to fill out a survey on their perceptions about their peers. For instance, they were asked to name the neighborhood associations that they considered to have the best access to the head of the district council, those they considered to have good leaders, those they considered to always get things done, those they thought had the most political engagement, etc. As self-reports are subject to bias, however, defining a clean measure of elites was not straightforward. To keep objectivity, we constructed the measure of elites as follows. If all of the participants systematically reported that a neighborhood president was well connected (by using a different subset of key perception questions), then we coded this neighborhood president as belonging to the elite of the district. If only some of the participants reported that a neighborhood president was well connected or no participant named the neighborhood association at all, then we coded this neighborhood president as not belonging to the elites of the district.

\subsection{Secondary data}

We use four complementary data sources: (i) district development plans; (ii) census data at the neighborhood association level; (iii) neighborhood presidents' basic demographic information; and (iv) public officials basic demographic characteristics. The information on district development plans was

\footnotetext{
${ }^{15} \mathrm{~A}$ two-step approach was used to conduct these random checks. In a first step, it was verified that a random subset of observations from the dataset could be located in the district council mailing books (the photography tracking numbers were critical throughout this process). In a second step, it was verified that a random subset of requests from the mailing books could be located in the dataset.
} 
gathered for the stratification of the sample. The information from the census at the neighborhood association level was collected to explore whether basic living standard measures might correlate ex-post with Chaskinet assignment. This information was gathered by manually matching census enumeration areas with neighborhood associations using cartographic information. The basic information about neighborhood presidents and public officials was collected from administrative records to assess the extent to which some of these characteristics might be correlated with any of the three outcome variables we look at in this paper. ${ }^{16}$ Neighborhood presidents' background characteristics may affect small infrastructure projects delivery through two different channels in addition to the political engagement channel. First, neighborhood presidents' education might be an important determinant of variation in monitoring capacity. Second, neighborhood presidents' union power experience might be an important determinant of the capacity to navigate the treacherous waters of bureaucracy. Public officials' characteristics may also affect small infrastructure projects delivery through two related channels. First, public officials' education and tenure might be an important determinant of variation in competence and efficiency within the administrative procedures required to complete a pre-certification request. Further, public officials' tenure may affect the allocation of small infrastructure projects through the building of social networks. That is, public officials with more tenure might have found their niches and built social networks, which directly translate into the use of favoritism and exercise of discretion when processing pre-certification requests.

\subsection{Subpopulation of analysis}

The subsample of projects considered in this paper is limited to those infrastructure projects with a budget under BS 200,000 (approximately USD 28,500 - obras menores). These types of projects comprise roughly 24 percent of the district councils' total budget. The reason why we are focusing on these projects is because the allocation of large-scale infrastructure projects follows a very different administrative procedure, which is relatively harder to manipulate by local neighborhood presidents. ${ }^{17}$ Our sample is representative only of those neighborhood associations having a president actively engaged in requesting pre-certification requests for small infrastructure projects at the district councils. Table 2 shows that roughly 67 percent of the neighborhood associations have a leader actively engaged in such requests (406 out of 607 ).

\subsection{Descriptive statistics}

The summary statistics of the data used in the study are presented in Table 4. Panel A reports the average values for the three outcome variables considered in the analysis (ex-post data). Panels B, C, and $\mathrm{D}$ present average values for baseline data. The aim is to verify that basic observable characteristics

\footnotetext{
${ }^{16}$ During the time of the data collection, both neighborhood association and district councils' leaders were serving an overlapping two-year term.

${ }^{17}$ Table 1 presents a summary of the types of small infrastructure projects included in this study. We have excluded from the subpopulation of analysis all mailing requests that did not relate to a pre-certification process request.
} 
of district councils and neighborhood associations were balanced across treatment status. The table shows that on average only 19 percent of the pre-certification requests are successfully completed (i.e. get pre-approved by the district council). This average is very similar across both treatment groups, and the difference in sample means across treatment status is not significant at the 5 percent level. A typical pre-certification request by a neighborhood president in the treatment group takes roughly 25 days to get processed compared to 27 days among those submitted by neighborhood presidents in the control group. The difference in sample means across treatment status for days requests take to get processed is significant at the 5 percent level. The average number of public officials involved in completing the administrative procedures required to complete a pre-certification request is 6 (5.5 among neighborhood presidents in treated district councils and 6.22 among those in control district councils). Again, the difference in sample means across treatment status for number of public officials involved in processing request is significant at the 5 percent level.

The average tenure (or years of union power experience) among neighborhood presidents in both treated and control groups is 2 years, with roughly 9 years of school completed in both groups. About 22 percent of neighborhood presidents both in treatment and control districts belong to elite groups. Roughly 7.5 percent of the neighborhood presidents are women (10 percent in the treated group and 5 percent in the control group). Although the percentage of neighborhood presidents that are women seems much higher in the treated group, the difference in sample means is not significant at the 5 percent level. As for public officials, the average tenure (or years of work at the district council) is 2 years (1.97 for public officials at treated district councils and 2.19 for those at control district councils). Roughly 5 percent of them have attended at least one year of college (5.21 percent among those in treatment district councils and 4.18 percent among those in control district councils). About 33 percent of public officials are women (27 percent in treated districts councils and 39 percent in control district councils). About 80 percent of public officials in both treated and control groups hold a staff/permanent position, and on average public officials are around 37 years old (35 for those in treated districts and 38 for those in control groups). Overall, these statistics show a good balance across treatment status of all of these basic characteristics of neighborhood presidents and public officials. The difference in means is only significant at the 5 percent level for public official's age.

The average number of people residing in a neighborhood is 1,500 , though there is quite a lot of variation across neighborhoods (1,881 on average in treated neighborhoods and 1,113 in control ones). At 7 percent, the unemployment rate is very similar across both treated and control groups (7.59 percent in treated neighborhoods and 6.80 in control ones). Neighborhood associations in the treated groups seem on average to be slightly better off than those in the control group. About 83 percent of them have access to electricity (in contrast to 78 percent in the control group), 51 percent have access to sanitary toilet facilities (in contrast to 48 percent in the control group), 14 percent have access to a landline phone (in contrast to 11 percent in the control group), and 57 percent are below the national poverty line (in contrast to 60 percent in the control group). None of the differences in sample means across these variables, however, is significant at the 5 percent level. 


\section{Discussion of experimental results}

\subsection{Overall effects}

Table 5 presents the main results from the experiment. Each row presents a different dependent variable, shown at the left. Column (1) reports the mean of the dependent variable in the control district councils. The effect of the Chaskinet - that is, the coefficient $\beta_{1}$ in Equation 1 - is presented in column (2). The $p$-value from a test that the Chaskinet effect is zero is presented in column (3). Columns (4) and (5) present again the Chaskinet effect and associated $p$-values for a specification of the model which does not allow for type of project fixed effects. This alternative specification allows assessing the extent to which the Chaskinet might have affected the composition of small infrastructure projects requested by neighborhood associations. Columns (6) and (7) show the results of an alternative model which includes stratum (or matched-pair) fixed effects instead. This specification of the model allows assessing whether respecting the blocking structure of the design affects the Chaskinet estimates or not. Each pair of rows below the outcome variables shows standard errors for the Chaskinet effect estimated separately based on whether the clustering of the structure of the data was taken into consideration or not. The first row reports simple robust standard errors. The second row instead reports robust standard errors clustered at the neighborhood association level. All reported $p$-values are computed using permutation inference.

The results in Table 5 show that the Chaskinet had a substantial negative effect on the number of days pre-certification requests take to get completed. Column (2) shows that the Chaskinet resulted in a 16.3 percentage points reduction in the number of days requests take to get completed. This effect is statistically significant, with $p$-values of 0.000 and 0.003 , based on whether the standard errors are allowed to be correlated at the neighborhood association level or not. Also, this reduction corresponds to an average reduction of 4.44 numbers of days requests take to get completed over the mean among the control group. The estimates in other columns show that the Chaskinet has a similar magnitude and statistical significance to that reported for the baseline specification (the reduction ranges from 15.3 to 17.2 percentage points or 4.17 to 4.69 number of days). Figure 2 shows the results graphically presenting for each treatment group the estimated probability density function, where the function is estimated using an Epanechnikov kernel. These results show that the number of days pre-certification requests take to get completed at treated district councils is lower at all percentiles of the distribution. The two-sample Kolmogorov-Smirnov statistic testing for equality of both density functions is 0.2539 $(p$-value $=0.000)$.

In practice, a reduction in the number of days requests take to get completed must arise by a reduction in inefficient practices among public officials, which cause unnecessary bureaucratic delays for neighborhood associations. One of such practices, as discussed in Section 2, is ping-pong behavior. The next panel in Table 5 shows that the Chaskinet had also a large negative effect on the number of public officials required to complete a pre-certification request process. Column (2) shows that the Chaskinet resulted in a reduction of 7.8 percentage points in the number of public officials required 
to complete a request. This reduction corresponds to an average reduction of 0.49 number of public officials required to complete a pre-certification request process. This effect is statistically significant, with $p$-values of 0.000 , independently of whether standard errors are clustered or not clustered at the neighborhood association level. This effect has a similar magnitude and statistical significance across all of the specifications of the model reported in columns (4) and (6) - the average reduction in the number of public officials in these alternative specifications ranges from 8.3 to 9.2 percentage points (or 0.52 to 0.57 number of public officials). Figure 3 reports the results graphically estimated also using an Epanechnikov kernel. The Figure shows that ping-pong practices are on average less frequent in treated district councils across all of the percentiles of the distribution. The two-sample Kolmogorov-Smirnov statistic for equality of density functions is 0.1864 ( $p$-value $=0.000)$.

A natural question that arises in this setting then is whether the Chaskinet might have affected the probability that a pre-certification request was successfully completed. Having a pre-certification request successfully completed means getting it endorsed by the district council. This is a decision made by the head of the district council based upon all of the information prepared by their subordinates. The last panel in Table 5 shows the OLS estimates of a linear probability model, based in Equation 1, on an indicator for whether the pre-certification process was successfully completed. In contrast to previous findings, the estimates show that the Chaskinet had a negligible, and mostly statistically insignificant, positive effect on the probability that a pre-certification request gets successfully completed. Column (2) shows that the Chaskinet resulted in an increase of 1 percent in the probability of successfully completing a pre-certification request. Yet, this effect is statistically insignificant, with $p$-values of 0.326 and 0.736 , based on whether the standard errors are clustered or not clustered. In columns (4) and (6), the Chaskinet effect is similar magnitude at 1.7 percent but only statistically significant when standard errors are not allowed to be correlated at the neighborhood association level.

The Chaskinet effects do not vary substantially overall across the different specifications of the model. Estimates reported in columns (2) and (4) do not vary substantially. This suggests that although the Chaskinet might have affected the composition of pre-certification requests submitted by neighborhood associations, this change seems negligible. The Chaskinet effects also do not seem to depend importantly either on whether we respect or do not respect the blocking structure of the experimental design. Estimates reported in columns (2) and (6) do not vary substantially. This suggests that type of requests are well balanced across type of requests within matched-pairs. Still, our preferred specification is the one that does not explicitly control for matched-pair design as it allows for more variation for the identification of the Chaskinet effects.

\subsection{Elite groups}

As discussed above, political connections are largely considered among neighborhood presidents as valuable assets to facilitate the provision of small infrastructure projects. To examine this, we look at whether and how the impacts of the Chaskinet differ across neighborhood associations headed by 
supporters and non-supporters of the head of the district council. Table 6 reports estimates from Equation 2, which tries to get some insights into the relationship between the Chaskinet and the elite status of the neighborhood president. This Table mirrors Table 5. Each pair of columns reports the coefficient of interest along with the $p$-value from a test that the coefficient is zero. We report two alternative standard errors based on the level of clustering used for the estimation: not clustered and clustered at the neighborhood association level. All reported $p$-values are again computed using permutation inference. In addition, we present results for the three previous specifications based on the level of fixed effects included in the model: (i) baseline specification; (ii) baseline specification not allowing for type of project fixed effects; and (iii) stratum (or matched-pair) fixed effects.

The results in Table 6 show strong evidence that there is a positive correlation between the elite status of a neighborhood president and the probability that his pre-certification requests get endorsed by the district council. Neighborhood presidents perceived as local elites are on average 19 percent more likely to get their pre-certification requests successfully completed as compared to those considered non-elites (columns (13) to (18)). The magnitude of this coefficient is consistent across the different specifications of the model, and it is always significant at the 1 percent level. Given that the mean probability of getting a pre-certification request approved is only 22 percent, this effect is quite large in magnitude. However, neighborhood presidents perceived as local elites cannot avoid pingpong practices among public officials. Depending on the specification, requests by elite neighborhood presidents take between 0.6 to 2.0 percent fewer public officials to get completed as compared to those from non-elite neighborhood presidents (columns (7) to (12)). Similarly, neighborhood presidents perceived as local elites cannot avoid unnecessary bureaucratic delay within the processing of their requests. Depending on the specification, elite neighborhood presidents requests take between 2.8 to 4.2 percent fewer days to get processed as compared to those from non-elite neighborhood presidents (columns (1) to (6)). Yet, these coefficients are for the most part not significant at standard levels.

Given that elite status of the neighborhood president seems to be an important determinant of the probability of successfully completing a pre-certification request, an important next question that arises is to what extent the Chaskinet is able to reduce the observed gap in the probability of getting a request successfully completed between local elites and non-elites. Coefficient $\beta_{1}$, in Equation 2 , measures this, and it is reported at the end of each panel in Table 6. Overall, the Chaskinet is not able to significantly reduce the gap in processing times between elite and non-elites. Column (1) shows that interaction between the Chaskinet and elite status resulted in a 6.3 percentage points reduction in the gap in processing times, but this effect is only significant at the 10 percent level and in the baseline specification. The estimates in all the other columns controlling for different levels of fixed effects show that these interactions are never significant at standard levels. In contrast, the results on the number of public officials involved in processing the requests are more encouraging and suggest that the Chaskinet reduced the gap in the number of public officials involved in processing requests across the elite status of the neighborhood president. Columns (7) and (9) show that interaction between the Chaskinet and the elite status of the president resulted in a reduction between 1.7 and 2.4 percentage points in the gap in number of public officials across elite status, depending on the 
specification, and this effect is always significant at the 5 percent level. Lastly, the estimates on the probability of having a pre-certification request successfully completed suggest show the Chaskinet is unsuccessful at promoting convergence in success gaps between elite and non elite neighborhood presidents. In particular, none of the interactions between the Chaskinet and elite status of the neighborhood president (columns (13) to (18)) are significant at standard levels.

\section{Interpretation}

A natural question that arises in this setting is why the Chaskinet is able to affect ping-pong practices and number of days pre-certification requests take to get processed, but not the probability that a demand gets successfully completed. To address this question, it might be useful to rethink the setting of the study and re-examine the design of the experiment. The main objective of the Chaskinet was to facilitate the involvement of neighborhood presidents in the process of reviewing, tracking, and monitoring pre-certification requests. To do so, selected information generated by the Chaskinet was made publicly available to give the big picture of the processing of these requests by type of project. This included summary statistics on composition of requests, average number of requests (by type of infrastructure project), average processing times (by type of infrastructure project), and number of public officials involved in the processing of request (by type of infrastructure project). ${ }^{18}$ By providing transparent and accurate real-time information, the Chaskinet significantly reduced the opportunity cost for neighborhood presidents to find out about the status of their pre-certification requests. Yet, by making this information publicly available, the Chaskinet also implicitly altered the probability that district council heads might detect inefficient practices among public officials (i.e. ping-pong practices and unnecessary bureaucratic delay). To this end, the Chaskinet simultaneously added an extra monitoring dimension into the study: top-down monitoring from district council heads to public officials.

The effect of the Chaskinet on bureaucratic delay (including both ping-pong practices and number of days requests take to get processed) might be the result of either the bottom-up or top-down monitoring operating simultaneously in this setting. On the one hand, there is a large literature in labor economics showing that monitoring tools tend to be highly effective at improving effort among workers (e.g. Grossman and Hart (1983), Nalbantian and Schotter (1997), Mirrlees (1999), Nagin et al. (2002)). In the setting of this study, most public officials are appointed by the central government but local authorities have lot of power over firing decisions if public officials are found to be incompetent in the job. By explicitly altering the probability of detecting inefficient administrative practices, the Chaskinet implicitly increased the expected cost of engaging in such practices among public officials. Therefore, the Chaskinet created strong incentives for public officials to improve their performance as a result of the use that managers (or head of district councils) might make

\footnotetext{
${ }^{18}$ In practice, heads of district councils and members of the oversight committees could unrestrictedly access all of the Chaskinet information. Public officials and neighborhood presidents could only access the information if they performed specific searches such as, for instance, tracking number, name of the neighborhood association, type of request, etc.
} 
of the information generated by the system. On the other hand, by facilitating the involvement of neighborhood presidents in the process of monitoring project allocations, the Chaskinet significantly reduced the opportunity cost for neighborhood presidents to engage in bottom-up monitoring as a political investment. Consequently, the reduction in bureaucratic delay resulting from the Chaskinet might respond either to neighborhood presidents becoming more engaged in the monitoring of their pre-certification requests or the fear that heads of district councils would become more engaged in the monitoring of their subordinates. Unfortunately, the design of the experiment does not allow us to disentangle both mechanisms.

The one major objective of heads of district councils during their time in office is to keep support among neighborhood presidents for the next electoral period. This is normally achieved by repaying political support to their peers through the use of favoritism when allocating small infrastructure projects. In contrast to public officials, heads of district councils are not appointed by the central government but rather are local leaders democratically elected among all neighborhood presidents in a district (by democratically elected, we mean here that all presidents get to vote, but not that the local community as a whole is itself involved in the voting process). The fact that the Chaskinet does not affect the probability of successfully completing pre-certification requests, and that elites and successful endorsement of projects are positively correlated suggest some scope for the existence of entrenched elites. To the extent that the Chaskinet significantly increases the probability that members of the oversight committee might channel this information to the central level, we would expect to observe at least some minimal changes in how small infrastructure projects are endorsed if elites were not entrenched.

There are at least three explanations regarding why altering the probability that the exercise of discretion might be detected does not change the allocation of small infrastructure projects by heads of district councils. First, it might be that the members of the oversight committees did not fully realize the potential of the information generated by the Chaskinet. Second, it might be that the members of the oversight committees did not have enough time to incorporate the Chaskinet information into their oversight activities because of the relatively short period of time of the intervention. Third, it might be that the members of the oversight committees are not well aware of the elite groups at the district level and, therefore, are not able to identify favoritism from the data generated by the Chaskinet. Certainly, all these are real possibilities which unfortunately cannot be ruled out with the information at hand.

\section{Concluding remarks}

Since the introduction of the decentralization and law of popular participation, the delivery of small infrastructure projects by sub-municipal governments in Bolivia has witnessed a radical overhaul. The law drastically empowered citizens by granting grassroots organizations the right to participate in the planning, budgeting, and monitoring of these projects in representation of their communities. Further, 
the law granted them veto power over sub-municipal budgets to discipline providers, and to ensure that local elites did not capture a disproportionate share of resources. Although the law was enacted more than a decade ago now, grassroots organizations still seem to face important constraints in participating in the monitoring of small infrastructure projects allocations, including lack of adequate monitoring tools.

This paper investigates the potential of a monitoring tool designed to reduce bureaucratic delay within the administrative processing of small infrastructure projects by sub-municipal governments. Bolivia presents a unique setting in which to study this question for several reasons. First, local leaders have strong political incentives to get actively engaged in the monitoring of these projects. Second, the law of popular participation introduced in 1994 created formal, and by now well established, mechanisms to voice complaints and discipline sub-municipal providers. Third, there is a huge demand for small infrastructure projects at the local level, and its delivery is something citizens greatly value.

The results from this paper suggest that the provision and dissemination of information might play a crucial role in improving public service outcomes. We find that the monitoring tool used in this study significantly reduced the amount of time projects require to get revised and endorsed by sub-municipal governments. Further, we find that this monitoring tool makes the administrative processing of these projects more effective by reducing the number of public officials needed to get the revision of the project completed. However, this monitoring tool is not successful at changing the allocation patterns of these projects, which seem to be strongly biased toward grassroots organizations supporting local authorities. Our results present evidence of the value of making information widely available to beneficiaries (both to grassroots organizations and local public sector managers). Yet, it is not clear whether in our setting the observed effects are purely driven by the engagement of grassroots organizations in the monitoring process or also by the use of the monitoring information by public sector managers. Overall, our results suggest that monitoring tools would only work up to the highest-level at which a real punishment to providers might be enforced. 


\section{Figures and Tables}

Figure 1: Photographs of district councils' manual mailing tracking system, El Alto, Bolivia, 2010
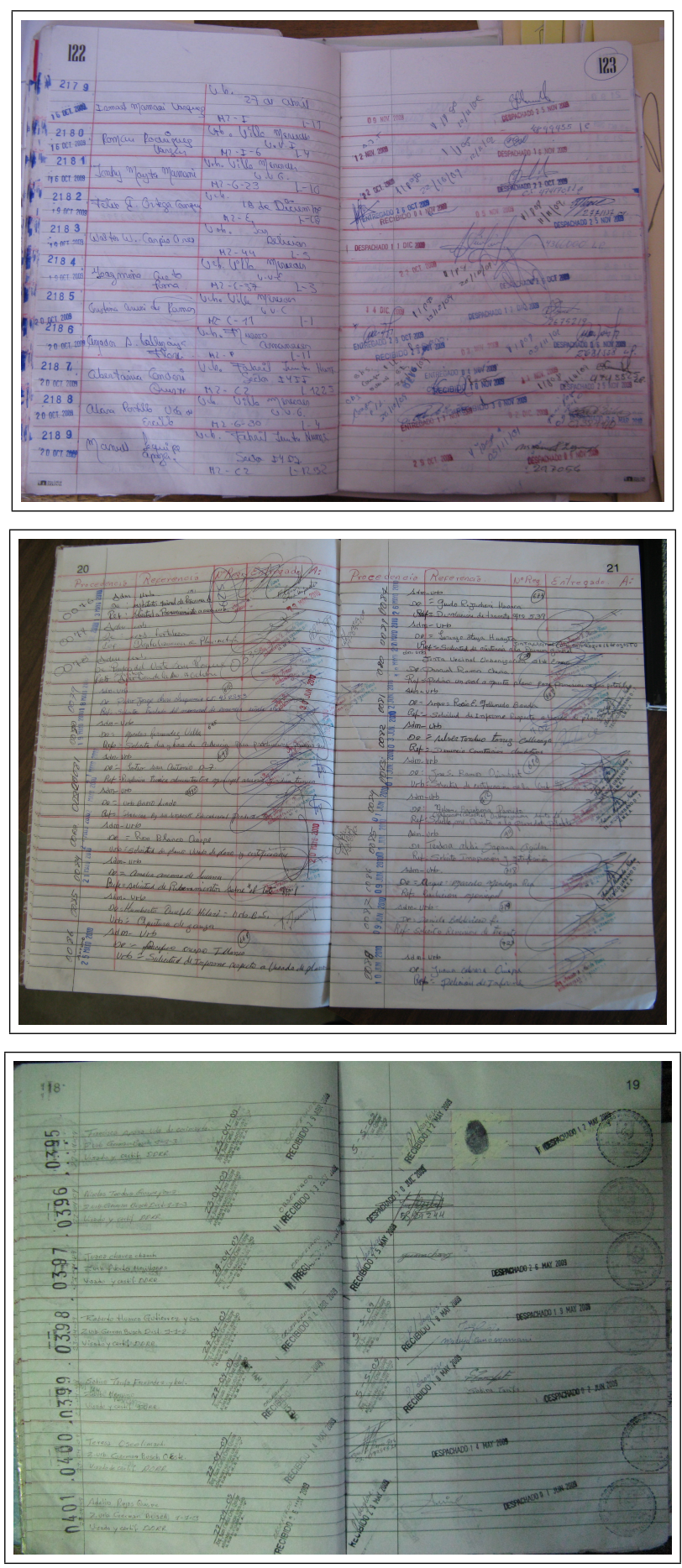
Figure 2: Empirical distribution of the number of days demands take to get processed, El Alto, Bolivia, 2010

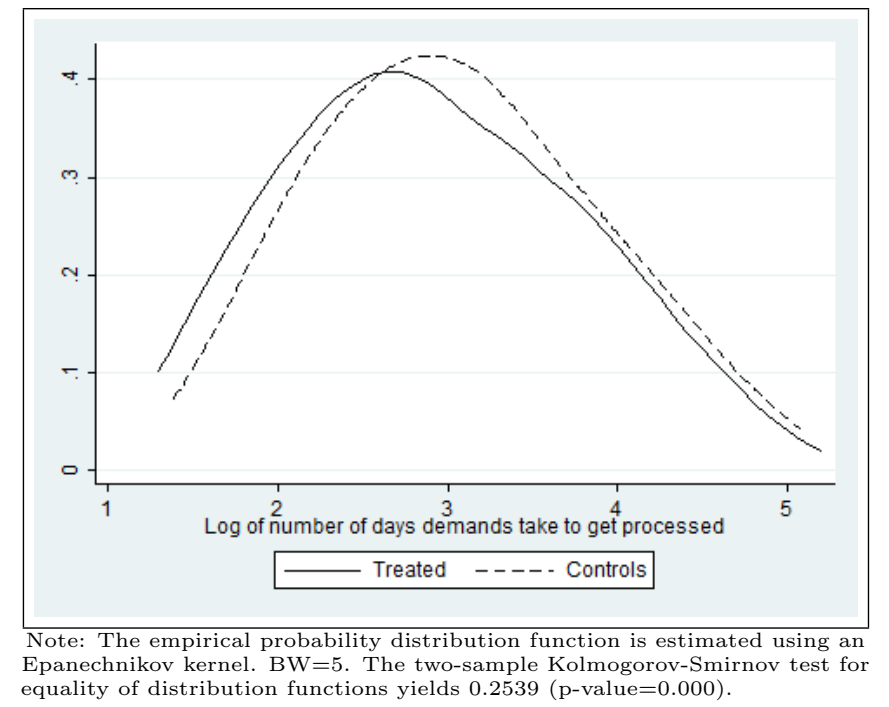

Figure 3: Empirical distribution of the number of public officials involved in addressing request, El Alto, Bolivia, 2010

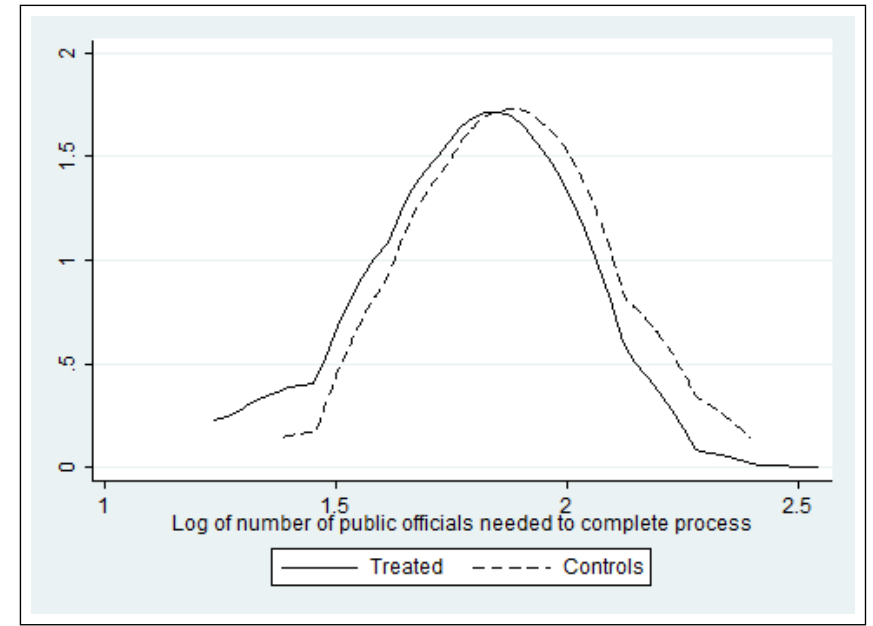

Note: The empirical probability distribution function is estimated using an equality of distribution functions yields 0.1864 ( $\mathrm{p}$-value= $=0.000)$ 
Table 1: Composition of small infrastructure projects delivered by district councils (\%), El Alto, Bolivia, $2010^{a}$

\begin{tabular}{|lccc|}
\hline & Proportion & $\begin{array}{c}\text { Linearized } \\
\text { standard error }\end{array}$ \\
\cline { 2 - 2 } Ancillary projects & $(1)$ & $(2)$ \\
Tree planting and landscaping & 0.0993 & & $(0.2990)$ \\
Civil security and safety & 0.1289 & & $(0.3351)$ \\
Construction materials & 0.0053 & $(0.0726)$ \\
Culverts & 0.0030 & $(0.0546)$ \\
Ditch digging & 0.1420 & $(0.3491)$ \\
Groundworks & 0.0979 & $(0.2972)$ \\
Heavy machinery & 0.0147 & $(0.1205)$ \\
Irrigation channels & 0.1609 & $(0.3674)$ \\
Retaining walls & 0.0023 & $(0.0479)$ \\
Road refurbishments & 0.0035 & $(0.0587)$ \\
Road surface paving & 0.0711 & $(0.2569)$ \\
Sewage treatment & 0.0089 & $(0.0938)$ \\
Shallow excavations & 0.0167 & $(0.1281)$ \\
Street lighting & 0.0422 & $(0.2009)$ \\
Street lighting maintenance & 0.0020 & $(0.0442)$ \\
Trench digging & 0.0116 & $(0.1072)$ \\
Boundary wall & 0.0068 & $(0.0822)$ \\
Water systems & 0.1647 & $(0.3709)$ \\
\hline Observations & & \\
\hline
\end{tabular}

${ }^{a}$ The small infrastructure projects reported in this table correspond only to those included in our final sample. Standard errors were calculated using a Taylor Series linearization approach allowing for clustering at the pair level. 
Table 2: Number of neighborhood associations by Chaskinet status, El Alto, Bolivia, $2010^{a}$

\begin{tabular}{|c|c|c|c|c|}
\hline Number of neighborhood & Matched-pair & Control & Chaskinet & Total \\
\hline associations & $(1)$ & $(2)$ & $(3)$ & $(4)$ \\
\hline Total number actively engaged in pre-certification requests & 1 & 51 & 60 & 111 \\
\hline Total number in district & 1 & 80 & 87 & 167 \\
\hline Total number actively engaged in pre-certification requests & 2 & 80 & 69 & 149 \\
\hline Total number in district & 2 & 92 & 82 & 174 \\
\hline Total number actively engaged in pre-certification requests & 3 & 27 & 26 & 53 \\
\hline Total number in district & 3 & 32 & 31 & 63 \\
\hline Total number actively engaged in pre-certification requests & 4 & 49 & 44 & 93 \\
\hline Total number in district & 4 & 91 & 112 & 203 \\
\hline Total number actively engaged & - & 207 & 199 & 406 \\
\hline Total number & - & 295 & 312 & 607 \\
\hline
\end{tabular}


Table 3: Relationship between Chaskinet, district council, and neighborhood association characteristics, El Alto, Bolivia, 2010 ${ }^{a}$

\begin{tabular}{|c|c|c|c|}
\hline & \multirow{2}{*}{$\frac{\text { Chaskinet }}{(1)}$} & \multirow{2}{*}{$\frac{\text { Chaskinet }}{(2)}$} & \multirow{2}{*}{$\begin{array}{c}\text { Chaskinet } \\
(3)\end{array}$} \\
\hline & & & \\
\hline \multirow[t]{2}{*}{ Neighborhood association population size } & 0.0000 & & $0.0000^{*}$ \\
\hline & $(0.000)$ & & $(0.000)$ \\
\hline \multirow[t]{2}{*}{ Neighborhood association quality of life index } & -0.0107 & & -0.0083 \\
\hline & $(0.008)$ & & $(0.004)$ \\
\hline \multirow[t]{2}{*}{ Neighborhood association literacy rate } & -0.1241 & & -0.0125 \\
\hline & $(0.081)$ & & $(0.011)$ \\
\hline \multirow[t]{2}{*}{ Neighborhood association unemployment rate } & 0.0033 & & -0.0045 \\
\hline & $(0.008)$ & & $(0.002)$ \\
\hline \multirow[t]{2}{*}{ Neighborhood association access to electricity rate } & $0.0070^{* * *}$ & & 0.0002 \\
\hline & $(0.001)$ & & $(0.001)$ \\
\hline \multirow[t]{2}{*}{ Neighborhood association access to sanitary toilet facilities rate } & 0.0038 & & -0.0003 \\
\hline & $(0.003)$ & & $(0.001)$ \\
\hline \multirow[t]{2}{*}{ Neighborhood association access to landline phone rate } & 0.0015 & & 0.0030 \\
\hline & $(0.008)$ & & $(0.001)$ \\
\hline \multirow[t]{2}{*}{ Neighborhood association poverty rate } & -0.0001 & & -0.0003 \\
\hline & $(0.002)$ & & $(0.000)$ \\
\hline \multirow[t]{2}{*}{ Neighborhood association president ever attended college indicator } & 0.1032 & & 0.0441 \\
\hline & $(0.054)$ & & $(0.031)$ \\
\hline \multirow[t]{2}{*}{ Neighborhood association president average time on duty } & 0.0981 & & 0.0242 \\
\hline & $(0.061)$ & & $(0.021)$ \\
\hline \multirow[t]{2}{*}{ Neighborhood association president is female indicator } & 0.1127 & & 0.0101 \\
\hline & $(0.107)$ & & $(0.024)$ \\
\hline \multirow[t]{2}{*}{ Number of public officials working at the district council } & & -0.2535 & -0.1867 \\
\hline & & $(0.199)$ & $(0.223)$ \\
\hline \multirow[t]{2}{*}{ Share of public officials that ever attended college } & & 0.1036 & 0.1288 \\
\hline & & $(0.183)$ & $(0.058)$ \\
\hline \multirow[t]{2}{*}{ Public officials' average time on duty } & & -0.0186 & -0.2077 \\
\hline & & $(0.556)$ & $(0.217)$ \\
\hline \multirow[t]{2}{*}{ Share of public officials that are female } & & 0.0005 & 0.0101 \\
\hline & & $(0.017)$ & $(0.006)$ \\
\hline \multirow[t]{2}{*}{ Share of public officials that are staff } & & -0.0016 & 0.0003 \\
\hline & & $(0.006)$ & $(0.002)$ \\
\hline Observations & 607 & 8 & 607 \\
\hline $\mathrm{p}$-value of all listed variables & 0.210 & 0.174 & 0.096 \\
\hline
\end{tabular}




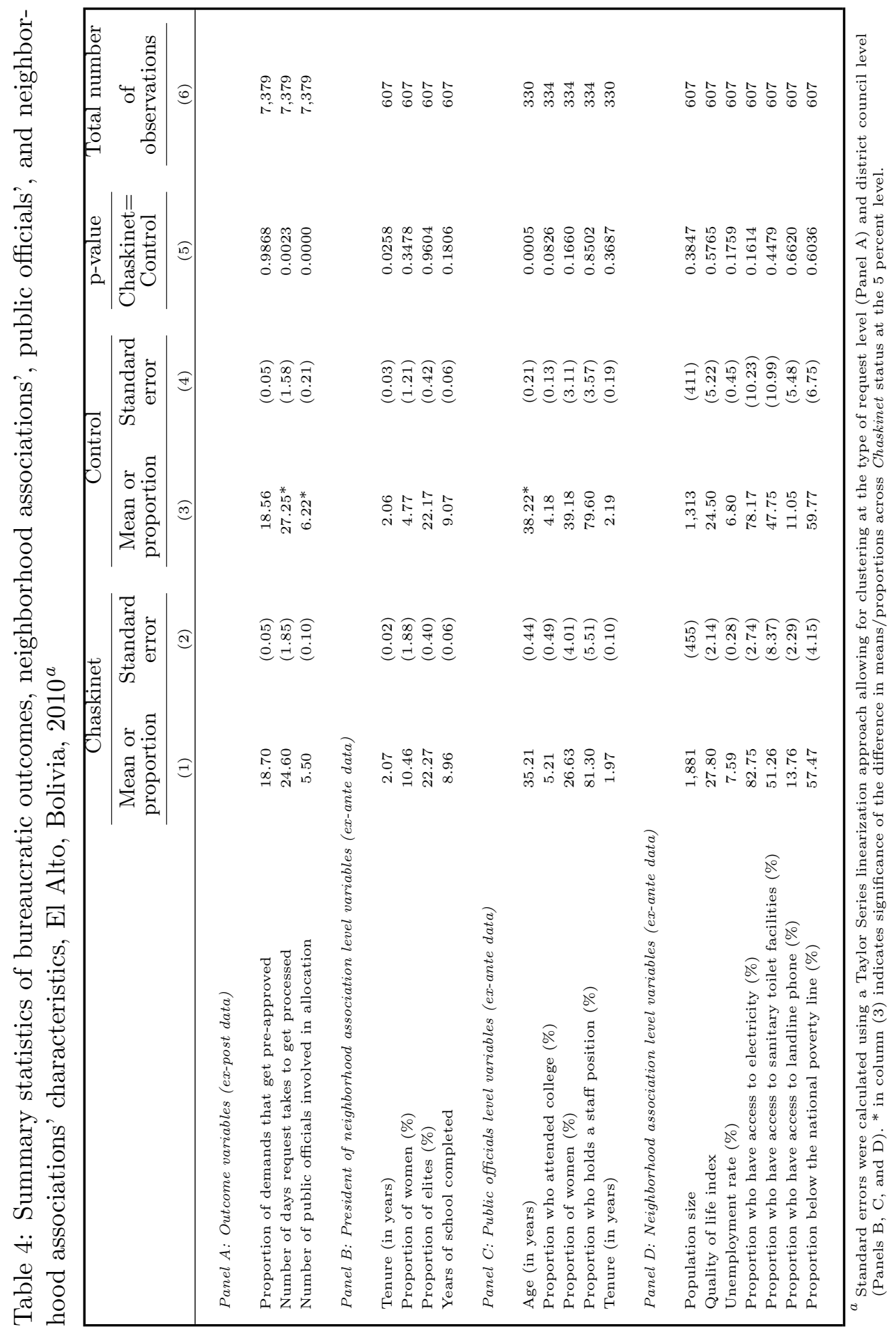




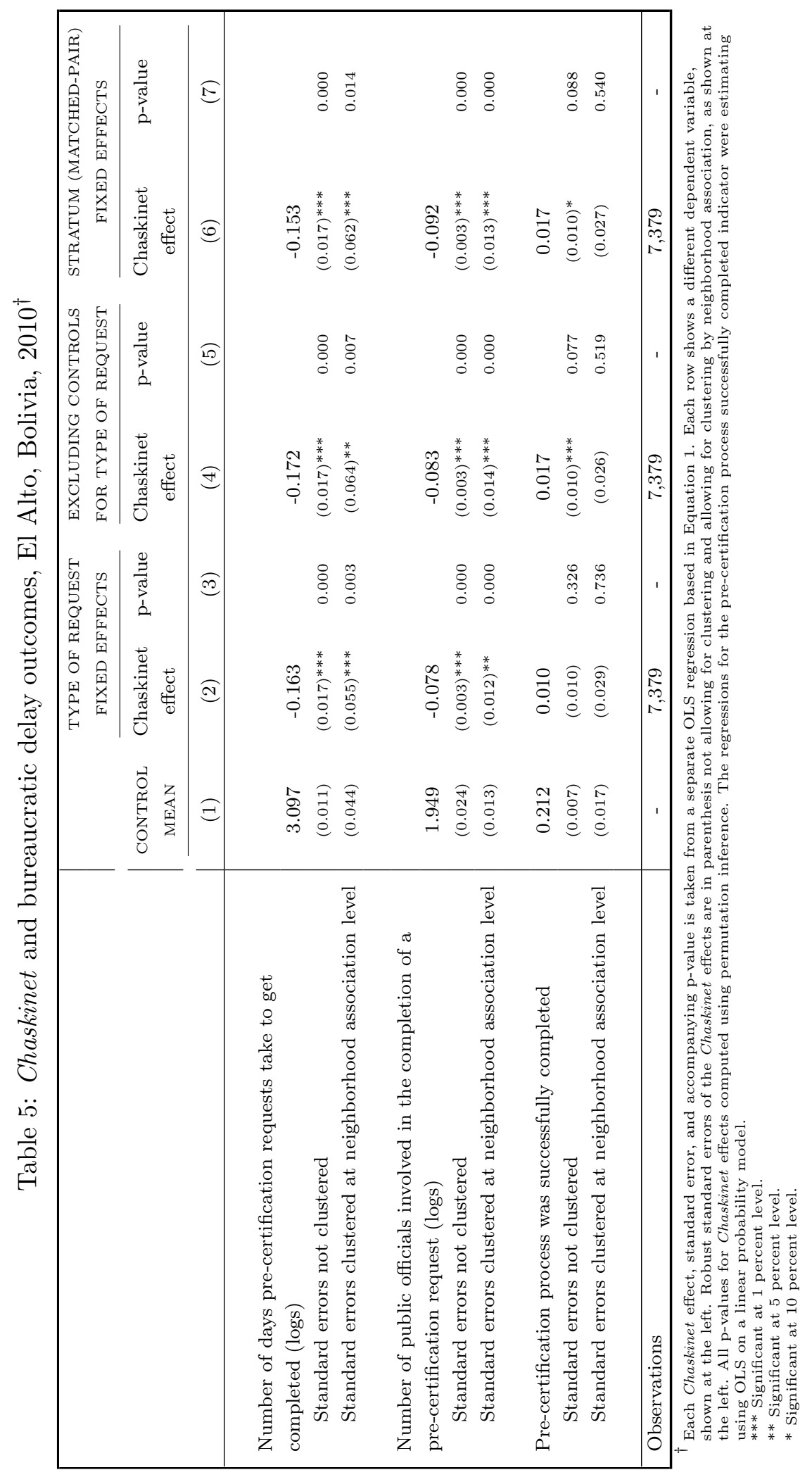


Table 6: Chaskinet, local elites, and bureaucratic delay outcomes, El Alto, Bolivia, $2010^{\dagger}$

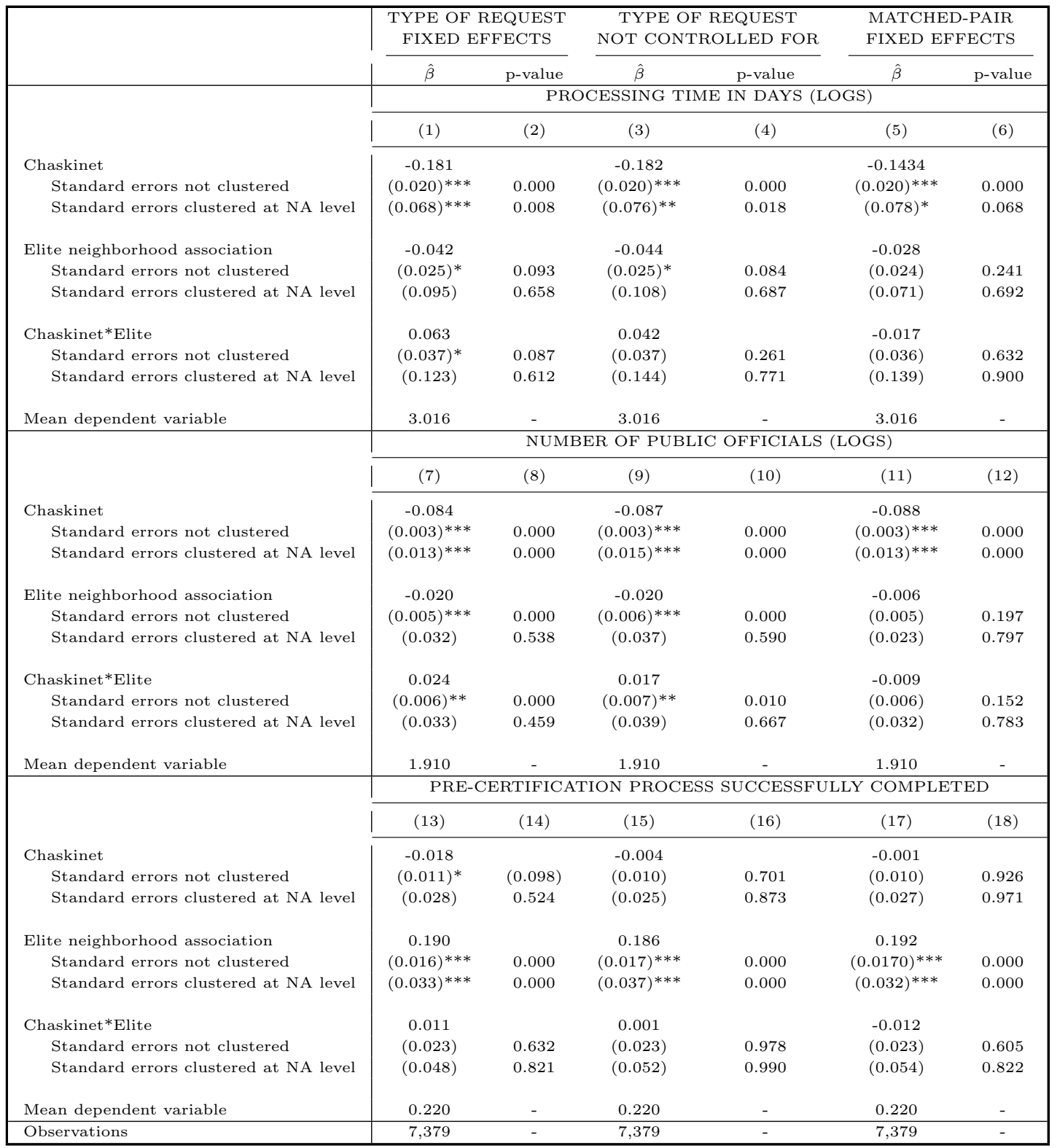

$\dagger$ Each Chaskinet effect, standard error, and accompanying p-value is taken from a separate OLS regression based in

Equation 2. Each row shows a different dependent variable, shown at the left. Robust standard errors of the Chaskinet effects are in parenthesis not allowing for clustering and allowing for clustering by neighborhood association, as shown at the left. All p-values for Chaskinet effects computed using permutation inference. *** Significant at 1 percent level. **

Significant at 5 percent level. * Significant at 10 percent level. 


\section{References}

Banerjee, A., A. Deaton, and E. Duflo (2004). Wealth, health, and health services in rural Rajasthan. American Economic Review 94(2), 326-330.

Banerjee, A. and E. Duflo (2006). Addressing absence. Journal of Economic Perspectives 20(1), $117-132$.

Banerjee, A. V., R. Banerji, E. Duflo, R. Glennerster, and S. Khemani (2010). Pitfalls of participatory programs: Evidence from a randomized evaluation in education in india. American Economic Journal: Economic Policy 2(1), 1-30.

Bardhan, P. (2002). Decentralization of governance and development. Journal of Economic Perspectives 16(4), 185-205.

Bardhan, P. and D. Mookherjee (2006). Pro-poor targeting and accountability of local governments in west bengal. Journal of Development Economics 79(2), 303-327.

Bertrand, M., E. Duflo, and S. Mullainathan (2004). How much should we trust differences-indifferences estimates? The Quarterly Journal of Economics 119(1), 249-275.

Blanes, J. (1998). La paz, juntas vecinales y comité de vigilancia. CEBEM.

de Janvry, A., F. Finan, and E. Sadoulet (2010). Local electoral incentives and decentralized program performance. NBER Working Papers 16635, National Bureau of Economic Research, Inc.

Donald, S. G. and K. Lang (2007). Inference with difference-in-differences and other panel data. The Review of Economics and Statistics 89(2), 221-233.

Faguet, J.-P. (2004). Does decentralization increase government responsiveness to local needs?: Evidence from bolivia. Journal of Public Economics 88(3-4), 867 - 893.

Faguet, J.-P. (2006). Decentralizing bolivia : Local government in the jungle. In P. Bardhan and D. Mookherjee (Eds.), Decentralization and local governance in developing countries. MIT Press, London, UK.

Faguet, J.-P. and F. Sanchez (2008). Decentralization's effects on educational outcomes in bolivia and colombia. World Development 36(7), 1294-1316.

Foster, A. D. and M. R. Rosenzweig (2001). Democratization, decentralization and the distribution of local public goods in a poor rural economy. Technical report, PIER Working Paper No. 01-056.

Galasso, E. and M. Ravallion (2005). Decentralized targeting of an antipoverty program. Journal of Public Economics 89(4), 705-727.

Gong, T. (2002). Dangerous collusion: Corruption as a collective venture in contemporary china. Communist and Post-Communist Studies 35(1), 85-103. 
Grossman, S. J. and O. D. Hart (1983, January). An analysis of the principal-agent problem. Econometrica 51(1), 7-45.

Kernan, W. N., C. M. Viscoli, R. W. Makuch, L. M. Brass, and R. I. Horwitz (1999). Stratified randomization for clinical trials. Journal of Clinical Epidemiology 52(1), 19 - 26.

Kezdi, G. (2005). Robust standard error estimation in fixed-effects panel models. Econometrics, EconWPA.

Kohl, B. (2003). Democratizing decentralization in bolivia: The law of popular participation. Journal of Planning Education and Research 23, 153-164.

Kremer, M., E. Bloom, I. Bhushan, D. Clingingsmith, R. Hung, E. King, B. Loevinsohn, and B. Schwartz (2006). Contracting for health: Evidence from cambodia. Mimeograph.

Lazar, S. (2004). Personalist politics, clientelism and citizenship: Local elections in el alto, bolivia. Bulletin of Latin American Research 23(2), 228-243.

Lazar, S. (2005). Citizens despite the state: Everyday corruption and local politics in el alto-bolivia. In D. Haller and C. Shore (Eds.), Corruption: Anthropological Perspectives. London: Pluto Press.

Lazar, S. (2006). El alto, ciudad rebelde: Organisational bases for revolt. Bulletin of Latin American Research 25(2), 183-199.

Lazar, S. (2007). El Alto, rebel city: Self and citizenship in Andean Bolivia. Duke University Press.

Mirrlees, J. A. (1999, January). The theory of moral hazard and unobservable behaviour: Part i. Review of Economic Studies 66(1), 3-21.

Nagin, D. S., J. B. Rebitzer, S. Sanders, and L. J. Taylor (2002, September). Monitoring, motivation, and management: The determinants of opportunistic behavior in a field experiment. American Economic Review 92(4), 850-873.

Nalbantian, H. R. and A. Schotter (1997, June). Productivity under group incentives: An experimental study. American Economic Review 87(3), 314-41.

Olken, B. A. (2007). Monitoring corruption: Evidence from a field experiment in indonesia. Journal of Political Economy 115(2), 200-249.

Philip, D., J. V. Domelen, E. Ostrom, A. Ryan, W. Wakeman, A. Bebbington, S. Alkire, T. Esmail, and M. Polski (2001). Community driven development. Poverty reduction strategy paper, The World Bank. Washington, D.C.

Reinikka, R. and J. Svensson (2004a). Local capture: Evidence from a central government transfer program in uganda. The Quarterly Journal of Economics 119(2), 678-704.

Reinikka, R. and J. Svensson (2004b). The power of information : Evidence from a newspaper campaign to reduce capture. Policy Research Working Paper Series 3239, The World Bank. 
Robinson, J. A. (2008). The political economy of decentralization in bolivia. Technical report, Paper written for the World Bank Group.

Romer, N. (2008). Bolivia: Latin america's experiment in grassroots democracy. New Politics XI(4), $23-39$.

Rose-Ackerman, S. (2005). The challenge of poor governance and corruption. Revista Direitogv Especial 1, 207-266.

Rosenbaum, P. R. (2002). Covariance adjustment in randomized experiments and observational studies. Statistical Science 17(3), 286-327.

Stiglitz, J. E. (2002). Participation and development: Perspectives from the comprehensive development paradigm. Review of Development Economics 6(2), 163-82.

Wooldridge, J. M. (2003). Cluster-sample methods in applied econometrics. American Economic Review 93(2), 133-138.

World Bank (2004). Making services work for poor people. World Development Report. Washington, DC: World Bank. 